\title{
FACULTY REQUIREMENTS PLANNING AND COURSE CYCLING INPART-TIME, ONLINE DEGREE PROGRAMS
}

\author{
Kingsley Gnanendran \\ Operations and Information Management Department, The University of Scranton \\ Scranton, Pennsylvania 18510, USA \\ skingsley.gnanendran@scranton.edu
}

\begin{abstract}
Many universities are moving toward the offering of part-time, online degree programs particularly at the graduate level. Typically the dean or another administrator is responsible for devising a course cycling plan along with adequate supporting faculty resources that enables students to progress and graduate within a reasonable and expected span of time. This problem is difficult to resolve due to uncertainty of demand for specific courses contained in the program. For example: (i) the program may be delivered with flexibility in time-to-completion, meaning that students are not assigned at admission to a specific cohort that proceeds in lockstep fashion toward graduation; (ii) the curriculum may contain elective courses which inject an element of choice; (iii) some courses may require the completion of other courses as prerequisites creating demand dependencies; and (iv) not every matriculated student successfully completes the program, and empirically observed retention rates will need to be factored in. Here we propose an approach for planning faculty requirements and course offerings that meets student flow and other constraints. The methodology combines linear programming with well-known operations management concepts such as material requirements planning and flow analysis.
\end{abstract}

Keywords: Academic course planning, Educational supply chain, Linear programming, material requirements planning, Online education

\section{INTRODUCTION}

Many universities are moving toward the offering of part-time, online degree programs particularly at the graduate level (e.g. online MBA programs). Such programs simultaneously offer challenges and opportunities for administrators in the planning and offering of an appropriate mix of courses each term along with a sufficient number of course sections. The aim is to ensure that student progress toward graduation is not impeded while also meeting constraints on institutional resources such as available faculty. When part-time degree programs are focused on flexibility and convenience, they tend not to 
be cohort-based. In such environments, it becomes difficult to predict actual enrollments on a term-by-term basis since students can stop out and resume at will. Other general challenges in academic planning that also apply to part time, online degree programs are: course prerequisites (which create demand dependencies), elective courses (with inconsistent and variable demand), and remedial courses (which may be required of some, but not all, admitted students). On the flip side however, the fact that these programs are offered in an asynchronous and online delivery mode mean that some of the usual constraints (classroom capacity, room and/or faculty time conflicts) that make such problems notoriously difficult to solve do not apply. In some sense, even geography is not a constraint since remote adjunct faculty could be tapped to teach online sections as long as any accrediting agency guideline on the ratio of part-time to full-time faculty is not exceeded.

Several distinct methodological approaches have been proposed in the literature to address academic course planning and the efficient utilization of resources in higher education. Johnes (2015) recently provided a review of operations research applications to the field of education in a broad range of areas including planning and allocation of resources. The prediction of student flow, a key concern in the literature, was addressed using Markov analysis in Bessent and Bessent (1980) and Kwak, Brown, and Schiederjans (1986). An alternative Journal of Business Studies approach used simulation methodology (see e.g. Boronico (2000), Saltzman and Roeder (2012)). Plotnicki and Garfinkel (1986) describe a simulation approach to maximize student flow (or minimize student flow time) subject to staffing constraints. Operations management concepts such as the celebrated Little's Law was applied by Litteral and Walk (2010) to predict persistence to graduation, student productivity, and program growth trends. Another wellknown technique from operations management, MRP (Material Requirements Planning) was adapted to higher education planning by Cox and Jesse Jr. (1981).

In this paper, we propose a modeling approach to determine faculty requirements and course offering frequencies that meets student flow and other constraints. The approach merges linear programming with MRP and flow analysis. Our methodology is most closely related to that of Cox and Jesse. $\operatorname{Jr}(1981)$ but differs from their approach in at least three key respects: (i) linear programming is used to perform the MRP explosion calculus; (ii) empirical attrition rates are incorporated to account for losses in student flow; and (iii) elective course requirements are time-phased based on both predicted graduation counts as well as course cycling patterns.

\section{A LINEAR PROGRAM FOR MATERIALREQUIREMEN TS PLANNING}

Material Requirements Planning (Orlicky,
Issue I - 2016 
1975) is a production scheduling and material planning technique widely used in industry to derive time-phased production schedules for dependent-demand items (lower-level assemblies and raw materials) based on demand forecasts for the finished goods. This differs from other approaches such as reorder point planning and consumption-based planning which do not taken into consideration either demand forecasts for the finished good, or the dependencies between the items constituting the bill of materials. MRP attempts to minimize inventory costs by producing at the latest possible point in time (backward scheduling). Other features of the MRP calculus (Vollmanet al., 2005) include: the netting out of any existing inventories (gross-to-net explosion) and accounting for component manufacturing times (lead time offsetting). When lot-for-lot ordering is used (i.e. there is no lot sizing), the following linear programming model can be used to model MRP.

Parameters

$N=$ number of items in the bill of materials

$T=$ number of time periods ("buckets") in

$$
\begin{aligned}
& \text { Minimize } \sum_{i=1}^{N} \sum_{t=1}^{T} h_{i t} I_{i t}+\sum_{i=1}^{N} \sum_{t=L(i)+1}^{T} c_{i t} P_{i t} \\
& \begin{array}{l}
I_{i, t-1}+P_{i, t}-I_{i, t}-\sum_{j \in S U C C(i)} u(i, j) P_{j, t+L(j)}=d_{i t} \quad i=1,2, \cdots N ; t=1,2, \cdots T \\
I_{i t} \geq 0 \\
\quad i=1,2, \cdots N ; t=1,2, \cdots T \\
P_{i t} \geq 0 \quad i=1,2, \cdots N ; t=L(i)+1, \cdots T
\end{array}
\end{aligned}
$$




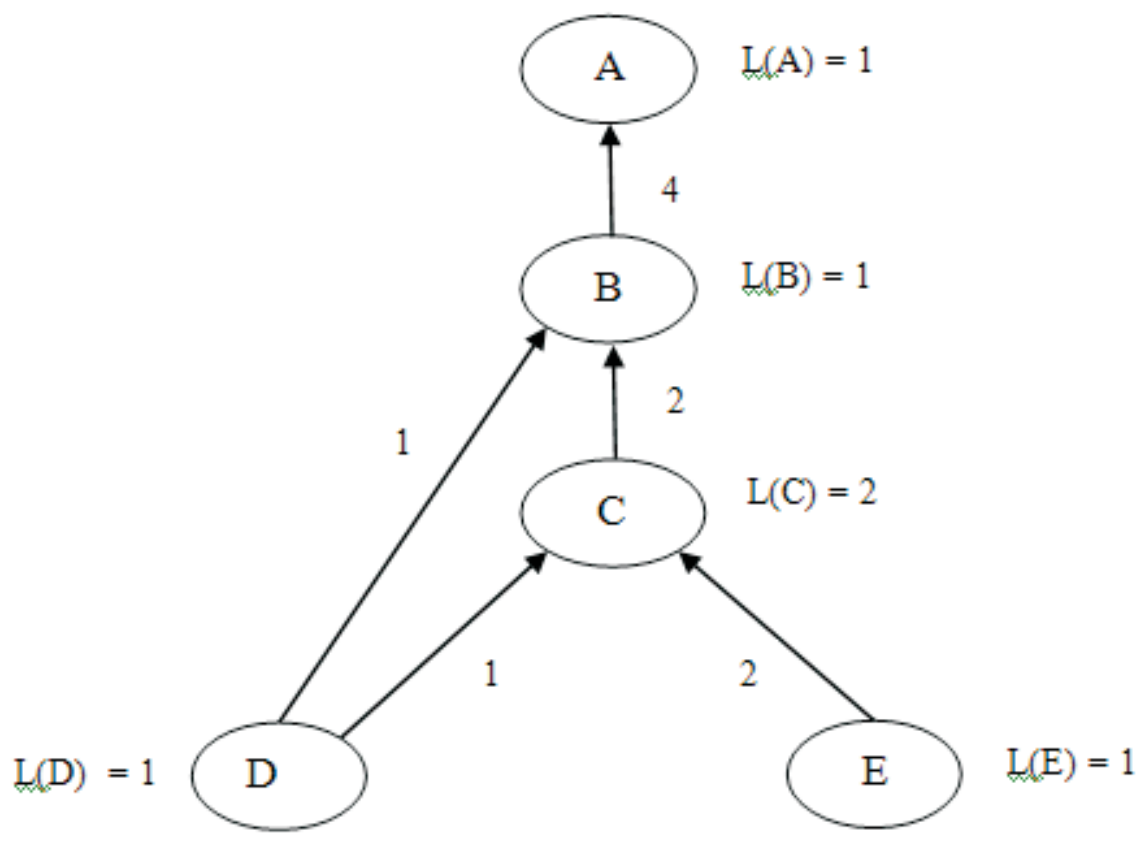

Figure 2.1: Bill of Materials for Example

$$
\begin{gathered}
\operatorname{SUCC}(A)=\{\varnothing\} ; \\
\operatorname{SUCC}(B)=\{A\} ; \\
\operatorname{SUCC}(C)=\{B\} ; \\
\operatorname{SUCC}(D)=\{B, C\} ; \\
\operatorname{SUCC}(E)=\{C\} ;
\end{gathered}
$$

The usage quantities $u(i, j)$ and lead times $L(i)$ are indicated in the figure. Only the end-item, A, has extemal demand, given as as $15,20,30$, and 25 units in weeks 6 through 9 respectively. Costs were set as follows: $h_{i t}=1.0 ; c_{i t}=2.0$ for all $i$ and $t$.
Table 2.1 gives the optimal values of the production variables yielded by solving the linear program, and which can be verified to correspond to planned order receipts in the standard MRP explosion calculus.

\section{A METHODOLOGY FOR PLANNING COURSE OFFERINGS}

Our approach for course cycle planning modifies the generic MRP model above to

Table 2.1: Optimal Values of $P_{\text {it }}$

\begin{tabular}{|c|c|c|c|c|c|c|c|c|c|}
\hline \multirow{2}{*}{ Item } & \multicolumn{9}{|c|}{ Week } \\
\cline { 2 - 10 } & 1 & 2 & 3 & 4 & 5 & 6 & 7 & 8 & 9 \\
\hline $\mathrm{A}$ & & & & & & 15 & 20 & 30 & 25 \\
\hline $\mathrm{B}$ & & & & & 60 & 80 & 120 & 100 & \\
\hline $\mathrm{C}$ & & & & 120 & 160 & 240 & 200 & & \\
\hline $\mathrm{D}$ & & 120 & 160 & 300 & 280 & 120 & 100 & & \\
\hline $\mathrm{E}$ & & 240 & 320 & 480 & 400 & & & & \\
\hline
\end{tabular}


account for student attrition rates as well as the presence of elective courses (similar to customer "options" in a manufacturing bill of materials). The methodology is described here using the example of a part-time, online MBA program that was being offered at a small, private university in the Northeast region of USA. The12-course program consisted of four "components": an initial cornerstone course, a core component, an elective component, and a final capstone course. All students began with thecornerstone course which introduces students to the triplethemes of corporate responsibility, social justice, and environmental sustainability,setting the stage for the subsequent coursework. Following this, the students moved into the core portion of the program which consisted of seven courses, one each from the standard business disciplines (accounting, operations, information systems, management, marketing, economics, and finance). On completion of the core, students couldopt for a specialization by completing three elective courses, all taken from the same focus area. Six areas were available: accounting, enterprise resource planning, healthcare management, human resources, international business, and operations management. A seventh option, called "general", applies when a student chooses not to specialize, but mixes and matches elective courses from across disciplines. Thus there was a total of seven degree paths (the general and six specializations) to choose from. Finally all were required to take a capstone class in business policy to complete requirements for the degree. A schematic is given in Figure

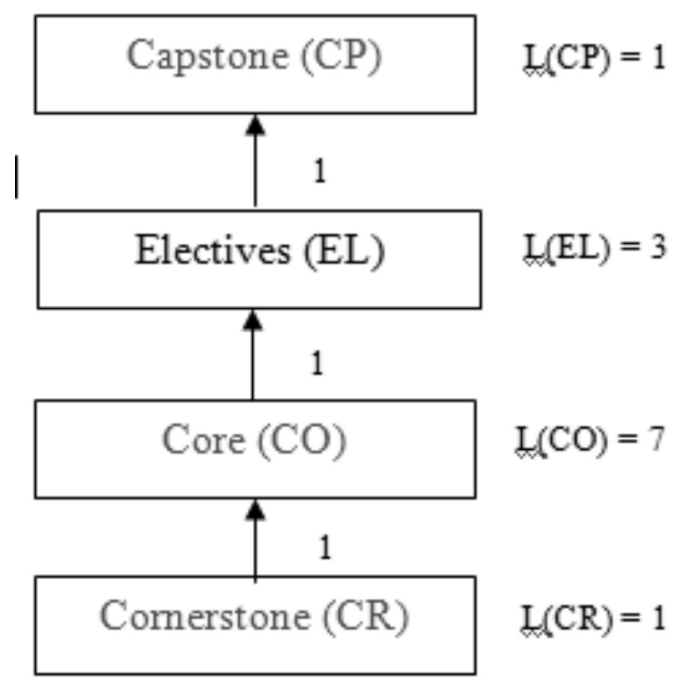

Figure 3.1: Schematic of Program Structure

are denoted as $C R, C O, E L$ and $C P$ respectively.

Not every student who matriculates couldbe expected to graduate from the program. This mavbe attributed to any number of reasons, e.g., lack of finances, work-related or personal isspes, aptitude, performance, etc. Using historical data, it is possible to forecast attrition rates at various stages of the program. In general, attrition is highest at the beginning of the program (during or at the end of the first course), and will tend to taper off as students complete each additional program component. We definethe following (the MRP time buckets will be "terms" in the academic context):

$a_{j}=$ attrition rate of students at the end of component $j(j=C R, C O, E L, C P)$

$A_{t}=$ number of students matriculating in term $\mathrm{t}$

$G_{t}=$ number of students graduating in term $\mathrm{t}$ 
These parameters are related via the following relationship:

$$
\begin{aligned}
G_{t+\sum_{j} L(j)} & =\prod_{j}\left(1-a_{j}\right) \times A_{t} \\
\text { where } a_{C P} & =0 .
\end{aligned}
$$

The course sequencing may be done using the MRP approach as follows: Each program component is analogous to an "item" in the MRP model, with $C P$ being the end-item. To estimate the demand values $d_{i, t}$, we project the number of graduates in each future term $G_{t}$ using Eq. (5). For periods in the near term $A_{t}$ may be set equal to the number of students who were admitted and have actually matriculated into the program. For terms further out into the future, we can use a suitable forecasting technique to predict $A_{t}$ based on observed patterns such as an increasing (or decreasing) trend in the number of applications, or any expected seasonality (e.g. fewer applicants wishing to start in a summer term). The demand parameter $d_{C P, t}$ in the MRP model is then set to the values $G_{t}$ as computed above. All other components have zero (external) demand. Lead time of each component is measured in "terms" (each term is eight weeks long) and reflects the number of courses comprising that portion. Thus: $L(C R)=1 ; L(C O)=$ $7 ; L(E L)=3 ; L(C P)=1$.

Interdependencies are reflected as:

$$
\begin{aligned}
\operatorname{SUCC}(C P) & =\{\varnothing\} ; \\
\operatorname{SUCC}(E L) & =\{C P\} ; \\
\operatorname{SUCC}(C O) & =\{E L\} ; \\
\operatorname{SUCC}(C R) & =\{C O\} .
\end{aligned}
$$

For all periods and components $h_{i t}$ is set to 1 , and $c_{i t}$ to zero. Initial inventories are also set to zero.

This academic course planning approach differs however in one significant way from the MRP model presented in $\S 2$, and that has to do with the incorporation of the attrition rates into the usage quantitics, as follows: $\quad u(i, \operatorname{SUCC}(i))=$ $1 /\left(1-a_{i}\right)$.For examplc, $u(C O, E L)$ is set cqual to $1 /\left(1-a_{C O}\right)$. On solving the MRP model with these settings, we obtain the optimal values of the $P_{i t}$ variables - or, in our case, $P_{C R, t} ; P_{C O, t} ; P_{E L, t} ;$ and $P_{C P, t}$.In the case of both the cornerstone $\left(P_{C R, t}\right)$ and capstone $\left(P_{C P, t}\right)$ courses, these values are final in the sense that they represent the requirements that will be needed in order to meet the predicted student flow.

For the $C O$ and $E I$ components however, since theyeach represent a collection of courses, the $P_{i t}$ values need to be further broken down to the level of specific courses. In the case of the core component, we simply offset the optimal $P_{C O, t}$ values to derive the time-phased requirement for each individual core course. For the $j^{\text {th }}$ core courseco $(j)$ :

$$
\begin{aligned}
& P_{c o(j), t+j-1}=P_{C O, t}(j=1,2, \ldots 7) \\
& \text { In the case of the clective }
\end{aligned}
$$
component, since the courses are not mandatory, some additional stepsare necessary to derive the timc-phased requircments. We use el $(k, m)$ to denote the $k^{\text {th }}$ clective in the $m^{\text {th }}$ specialization. Definc:

$f_{m}=$ fraction of students choosing specialization $m(m=1,2, \ldots 6)$

$f_{g}=$ fraction of students choosing the "general" option (denoted by setting $m=g$ ) 
$N_{m}=$ number of available electives in specialization $m$

$N_{g}=$ number of miscellancous clectives that do not count toward any specialization

$p_{k m}=$ popularity of $\quad e l(k, m)$ among students belonging to specialization $m$

$q_{k m}=$ popularity of $e l(k, m)$ among the "general" students

Both $p_{k m}$ and $q_{k m}$ are the historical fractions of students in the respective specialization (cither $m$ or gencral) who choose to take the given clective.

With these definitions, the following equation can be used to computc the requirement for elective $\operatorname{el}(k, m)$ within the3-term lead time for component $E L$, i.c. the window that begins in term $t$ and runs through $(t+2)$.

$R_{e l(k . m), t}=\left(f_{m} p_{k m}+f_{g} q_{k m}\right) P_{E L, t}$

In other words, $e l(k, m)$ must be offered at least once within the lead time window $[t, t+2]$ with sufficicnt capacity to handle $R_{e l(k . m), t}$ enrollments in order for these students to progress without delay to their expected graduation date as captured in the $P_{C P, t}$ values.

The $N_{m}$ electives belonging to specialization $m$ shouldthen be spread evenly within this 3-term windowin order to balance both faculty and student loads. This may be accomplished by assigning $e l(k, m)$ to terms initially as follows:

$\begin{array}{cc}\text { term } 1 & \text { if } k \bmod 3=1 ; \\ \text { term } 2 & \text { if } k \bmod 3=2 ; \\ \text { term } 3 & \text { if } k \bmod 3=0 .\end{array}$

These initial settings are then repeated with a "period" of 3 terms, i.e. any given elective will only be offered in one of three possible scquences: cither in terms $\{1,4,7, \ldots\}$; or in terms $\{2,5,8, \ldots\}$; or in terms $\{3,6,9, \ldots\}$. This guarantees the offering of all electives within every 3-term window regardless of the starting point of the window.

Alternatively, from the perspective of the term, we couldalso state that a termt is assigned to electives, as follows:

$$
\begin{aligned}
& \operatorname{el}(1, m), \operatorname{el}(4, m), \operatorname{el}(7, m) \text {, } \\
& \text {... if } t \bmod 3=1 \text {; } \\
& \operatorname{el}(2, m), \operatorname{el}(5, m), \operatorname{el}(8, m) \text {, } \\
& \text {.. if } \bmod 3=2 \text {; } \\
& \operatorname{el}(3, m), \operatorname{el}(6, m), \operatorname{el}(9, m) \text {, } \\
& \text {.. if } t \bmod 3=0 \text {. }
\end{aligned}
$$

In any given term, one and exactly one of the above clective sequences will be offered.

The time-phased requirements $T R_{\text {el (k.m),t }}$ may now be computed by applying the above assignment rulcs to the $R_{e l(k . m), t}$ values computed in eq. (6). This is illustrated by means of a numerical cxamplencxt.

\subsection{Numerical Example for the Time- Phasing of Elective Courses}

Consider the example below (Table 3.1.1) with two specializations, Marketing (MKT) and Finance (FIN), plus the nonspecialization option (GEN). MKT has five clectives (numbered sequentially from 561 to 565), FIN has four (581-584), and there are threc miscellancous clectives (591-593). GEN (general) students can pick their clectives from any of the specialization arcaswhereas students in the other two specializations must pick all of their electives from their own respective areas. The historical fraction of students cnrolled in each specialization is given in the first column in Table 3.1.1.Column 4 ("Sp.") gives the popularity of each elective for students in that particular spccialization, $p_{k m}$, whercas column 5 ("Gen") gives the popularity of cach elective for the GEN students, $q_{k m}$. 
Table 3.1.1: Requirements for the Elective Component $\left(R_{e l(k . m), t}\right)$

\begin{tabular}{|c|c|c|c|c|c|c|c|c|c|}
\hline \multicolumn{3}{|c|}{$\begin{array}{l}\text { Specializations (Sp.)\& } \\
\text { Electives (El.) }\end{array}$} & \multicolumn{2}{|c|}{ Popularity } & \multicolumn{5}{|c|}{ Requirements (by term) } \\
\hline \multirow{3}{*}{$\begin{array}{l}\text { Enrolled } \\
\text { Fraction }\end{array}$} & \multirow{3}{*}{ Sp. } & \multirow{3}{*}{ El. } & \multirow{2}{*}{$S p$} & \multirow{2}{*}{ Gen } & 1 & 2 & 3 & 4 & 5 \\
\hline & & & & & \multicolumn{5}{|c|}{$P_{E L, t}$} \\
\hline & & & $p_{k m}$ & $q_{k m}$ & 40 & 100 & 120 & 90 & 140 \\
\hline \multirow{5}{*}{$60 \%$} & \multirow{5}{*}{ MKT } & 561 & 0.8 & 0.1 & 19.6 & 49 & 58.8 & 44.1 & 68.6 \\
\hline & & 562 & 0.1 & 0.2 & 3.2 & 8 & 9.6 & 7.2 & 11.2 \\
\hline & & 563 & 0.5 & 0.1 & 12.4 & 31 & 37.2 & 27.9 & 43.4 \\
\hline & & 564 & 0.6 & 0.3 & 15.6 & 39 & 46.8 & 35.1 & 54.6 \\
\hline & & 565 & 0.2 & 0 & 4.8 & 12 & 14.4 & 10.8 & 16.8 \\
\hline \multirow{4}{*}{$30 \%$} & \multirow{4}{*}{ FIN } & 581 & 1.0 & 0.2 & 12.8 & 32 & 38.4 & 28.8 & 44.8 \\
\hline & & 582 & 0.1 & 0.1 & 1.6 & 4 & 4.8 & 3.6 & 5.6 \\
\hline & & 583 & 0.9 & 0 & 10.8 & 27 & 32.4 & 24.3 & 37.8 \\
\hline & & 584 & 0.8 & 0 & 9.6 & 24 & 28.8 & 21.6 & 33.6 \\
\hline \multirow{3}{*}{$10 \%$} & \multirow{3}{*}{ GEN } & 591 & & 0.5 & 2 & 5 & 6 & 4.5 & 7 \\
\hline & & 592 & & 0.6 & 2.4 & 6 & 7.2 & 5.4 & 8.4 \\
\hline & & 593 & & 0.7 & 2.8 & 7 & 8.4 & 6.3 & 9.8 \\
\hline
\end{tabular}

Column 6-10 give the requirements for the elective component. The first row of numbers $(40,100,120$, etc. $)$ gives the values of $P_{E L, t}$, i.e. for the entire elective component, whereas the remaining rows displaythe requirements $R_{e l(k . m), t}$ for each individual elective course based on eq. (6). Next, we time-phase these requirements following the approach described previously, and the results are displayed in Table 3.1.2.

Table 3.1.2: Time-Phased Requirements for Individual Elective Courses $\left(T R_{e l(k . m), t}\right)$

\begin{tabular}{|c|c|c|c|c|c|c|c|c|}
\hline \multicolumn{2}{|c|}{$\begin{array}{l}\text { Specializations } \\
\text { \& Electives }\end{array}$} & \multicolumn{7}{|c|}{ Time-Phased Requirements (by term) } \\
\hline Sp. & El. & 1 & 2 & 3 & 4 & 5 & 6 & 7 \\
\hline & 561 & 19.6 & & & $\begin{array}{c}49+ \\
58.8+ \\
44.1\end{array}$ & & & 68.6 \\
\hline & 562 & & $3.2+8$ & & & $\begin{array}{l}9.6+ \\
7.2+ \\
11.2\end{array}$ & & \\
\hline MKT & 563 & & & $\begin{array}{c}12.4+ \\
31+ \\
37.2\end{array}$ & & & $\begin{array}{c}27.9+ \\
43.4\end{array}$ & \\
\hline
\end{tabular}




\begin{tabular}{|c|c|c|c|c|c|c|c|c|}
\hline \multirow[t]{3}{*}{ MKT } & 563 & & & $\begin{array}{c}12.4+ \\
31+ \\
37.2\end{array}$ & & & $\begin{array}{c}27.9+ \\
43.4\end{array}$ & \\
\hline & 564 & 15.6 & & & $\begin{array}{c}39+ \\
46.8+ \\
35.1\end{array}$ & & & 54.6 \\
\hline & 565 & & $\begin{array}{c}4.8+ \\
12\end{array}$ & & & $\begin{array}{c}14.4+ \\
10.8+ \\
16.8\end{array}$ & & \\
\hline \multirow{4}{*}{ FIN } & 581 & 12.8 & & & $\begin{array}{c}32+ \\
38.4+ \\
28.8\end{array}$ & & & 44.8 \\
\hline & 582 & & $1.6+4$ & & & $\begin{array}{c}4.8+ \\
3.6+ \\
5.6\end{array}$ & & \\
\hline & 583 & & & $\begin{array}{c}10.8+ \\
27+ \\
32.4\end{array}$ & & & $\begin{array}{c}24.3+ \\
37.8\end{array}$ & \\
\hline & 584 & 9.6 & & & $\begin{array}{c}24+ \\
28.8+ \\
21.6\end{array}$ & & & 33.6 \\
\hline \multirow[t]{2}{*}{ GEN } & 591 & 2 & & & $\begin{array}{c}5+6+ \\
4.5\end{array}$ & & & 7 \\
\hline & 592 & & $2.4+6$ & & & $7.2+$ & & \\
\hline & & & & & & $\begin{array}{c}5.4+ \\
8.4\end{array}$ & & \\
\hline & 593 & & & $\begin{array}{c}2.8+7 \\
+8.4\end{array}$ & & & $\begin{array}{c}6.3+ \\
9.8\end{array}$ & \\
\hline
\end{tabular}

Each course section is capped at 20 students, so the required number of course sections for each elective-term combination can be found by the ceiling function: $\left\lceil T R_{e l(k . m), t} / 20\right]$. Manual adjustments may need to be made to the computed values, e.g. GEN 591 in term 1 with only 2 students may be moved to a different term or canceled altogether.

\section{CONCLUSION}

A methodology is proposed in this paperfor planning instructor (faculty) requirements as Journal of Business Studies well as frequency of course offerings to meet expected graduations dates of admitted students. It takes into consideration actual student matriculations (in the near term), estimated enrollment projections (in the longer term), and historical attrition ratesin order to derive time-phased course offerings and course sectionsneeded for both mandatory and elective courses in the program structure. The proposed approach should enable the efficient utilization of scarce faculty resources while meeting student flow constraints. 
Moreover, the approach could readily be adapted to handle further scenarios that have not been explicitly addressed in the current paper. Here are some possible extensions for future work: (i) Programs with a "flexible" core: Students may only be required to take a subset of the core courses rather than all of them. For example, in the institutional example discussed in this paper, students are now required to take only a minimum of four core courses (instead of all seven). These courses areto be picked from three distinct clusters (at least two from the accounting, economics, and finance cluster; at least one fromthe operations and information systems cluster; and at least one from the management and marketing cluster). (ii) Remedial work: Students with deficiencies in their prior academic preparation and/or work experience are assigned to one or more short courses. In the exampleprogram discussed, each such "qualifying course" was only of four weeks duration, i.e.,witha lead time of 0.5 term. (iii) Re-entering students:In a non-lockstep program, a few students may take time off at some point after matriculation. Although they represent only a small fraction of the total student population, re-entering students must be factored in when computing course offerings and faculty requirements.

\section{REFERENCES}

Bessent, E.W. and A.M. Bessent (1980). Student flow in a university department: results of a Markov analysis. Interfaces 10(2), 52-59.

Boronico, J. (2000). Quantitative modeling and technology driven departmental course scheduling. Omega 28(3), 327-
346.

Cox, J.F. and R.R. Jesse Jr. (1981). An application of material requirements planning to higher education. Decision Sciences 12(2), 240-260.

Johnes, J. (2015). Operational research in education. European Journal of Operational Research 243(3), 683-696.

Kwak, N.K., R. Brown, and M.J. Schiederjans (1986). A Markov analysis of estimating student enrollment transition in a trimester institution. Socio-Economic Planning Sciences 20(5), 311-318.

Litteral, L.A. and E.M. Walk (2010). The application of Little's Law to enrollment management: improving student persistence in part-time degree programs. Palmetto Business and Economic Review13, 38-52.

Orlicky, J. (1975). Material Requirements Planning. New York, NY: McGraw-Hill.

Plotnicki, W.J. and R.S. Garfinkel (1986). Scheduling academic courses to maximize student flow: a simulation approach. Socio-Economic Planning Sciences 20(4), 193-199.

Saltzman, R.M. and T.M. Roeder (2012). Simulating student flow through a college of business for policy and structural change analysis. Journal of the Operational Research Society 63(4), 511-523.

Vollman, T.E., W.L. Berry and D.C. Whybark (2005). Manufacturing Planning and Control for Supply Chain Management, Fifth Edition. Boston. MA: McGrawHill/Irwin. 